\title{
Study on properties of magnesium phosphosilicate cement using different reactive magnesia
}

\author{
Yu DAI ${ }^{1}$ and Chengyou WU ${ }^{1,2, \dagger}$ \\ ${ }^{1}$ School of Civil Engineering, Qinghai University, Xining 810016, PR China \\ ${ }^{2}$ Qinghai Provincial Key Laboratory of Energy-saving Building Materials and Engineering Safety, Xining 810016, PR China
}

\begin{abstract}
Magnesium phosphosilicate cement (MPSC) is generally composed of magnesium oxide, phosphate and silicate, and the admixture is generally borax to extend the setting time. In the preparation of traditional magnesium phosphate cement (MPC), reburned magnesium oxide is generally used. In this study, light-burned powder calcinated with borax will be used instead of reburned magnesium oxide to prepare MPC. The calcination temperature range is $1000-1200{ }^{\circ} \mathrm{C}$ and the holding time is $2 \mathrm{~h}$. This paper explores the influence of magnesia reactivity at different calcination temperatures on the performance of MPSC, including setting time, electron microscope, heat of hydration, phase composition and strength development. The results show that borax can significantly reduce the reactivity of magnesia. Experimental data shows that as the reactivity of magnesia increases, the mechanical properties of MPSC cement become better, and the porosity will also decrease. However, when the reactivity is too high, the cement cannot be formed because of the early setting time.

(C2021 The Ceramic Society of Japan. All rights reserved.
\end{abstract}

Key-words: Low temperature calcination, Light-burnt magnesia, Dipotassium phosphate, Magnesium phosphosilicate cement

[Received February 1, 2021; Accepted May 24, 2021]

\section{Introduction}

Magnesium phosphate cement (MPC) has a long history of development. As early as 1939, Prosen ${ }^{1)}$ used $\mathrm{MgO}$ and phosphoric acid to prepare a cementing material that can be hardened and formed in a few minutes. Such gelling materials which have excessive condensation time cannot be applied to actual project until the 1970s. Stierli ${ }^{2)}$ et al. used the retarder boric acid to control the reaction rate between magnesia and phosphate to prepared MPC cementitious material with long setting time and high strength that can meet engineering needs. Owing to rapid hardening period, high early strength, better bonding properties with the concrete, and small shrinkage compared to those of the Portland cement, MPC cement has been widely used in rapid repair, reinforcement and renovation of the project and has broad application prospects in the fields of refractory materials, bio-adhesives and hazardous substances curing, and national defense engineering construction. $^{3)-5)}$

The raw materials of MPC cement mainly include deadburned magnesium oxide powder and phosphate, and the admixture is generally borax with retarding effect. ${ }^{6)-8)}$ Phosphate is one of the main components of MPC, which mainly provides acidic components for the reaction of

$\dagger$ Corresponding author: C. Wu; E-mail: wuchengyou86@ 163.com
MPC. Currently, the widely used phosphates of MPC mainly include $\mathrm{NH}_{4} \mathrm{H}_{2} \mathrm{PO}_{4}, \mathrm{KH}_{2} \mathrm{PO}_{4}, \quad\left(\mathrm{NH}_{4}\right)_{2} \mathrm{HPO}_{4}$, $\mathrm{K}_{2} \mathrm{HPO}_{4}$, and the composite of the above-mentioned phosphates. But the most used are $\mathrm{NH}_{4} \mathrm{H}_{2} \mathrm{PO}_{4}$ and $\mathrm{KH}_{2} \mathrm{PO}_{4}$. GAO R ${ }^{9)}$ et al. used $\mathrm{NH}_{4} \mathrm{H}_{2} \mathrm{PO}_{4}, \mathrm{KH}_{2} \mathrm{PO}_{4},\left(\mathrm{NH}_{4}\right)_{2} \mathrm{HPO}_{4}$, $\mathrm{K}_{2} \mathrm{HPO}_{4}$ and electrolytic magnesia to prepare MPC. The result shows that the setting time of monohydrogen phosphate is longer than that of dihydrogen phosphate, but the strength is much lower than that of dihydrogen phosphate. Xia Jinhong ${ }^{10}$ found that using $\left(\mathrm{NH}_{4}\right)_{2} \mathrm{HPO}_{4}$ to replace $\mathrm{NH}_{4} \mathrm{H}_{2} \mathrm{PO}_{4}$ to prepare MPC can prolong the setting time, but ammonia gas will be released during the reaction. In summary, the current research on MPC mainly uses ammonium dihydrogen phosphate $\left(\mathrm{NH}_{4} \mathrm{H}_{2} \mathrm{PO}_{4}\right)$ and potassium dihydrogen phosphate $\left(\mathrm{KH}_{2} \mathrm{PO}_{4}\right)$, while there are relatively few studies on potassium monohydrogen phosphate $\left(\mathrm{K}_{2} \mathrm{HPO}_{4}\right)$.

Generally, the finer the particle size and the larger the BET surface area of magnesia, the easier it is to contact with other reactants and the greater its reactivity, so that magnesia reacts with phosphate to form a hydration product faster. In addition, for the same amount of retarder, when the BET surface area of magnesia increases, the amount of retarder that can be obtained for each magnesia particle is reduced, which can accelerate the setting time of MPC. ${ }^{11)}$ At the same time, the smaller the magnesia fineness, the more water required to reach the standard consistency, and the shorter the initial setting and final 
setting time. ${ }^{12)}$ For the control of the setting and hardening time of MPC, currently the main method is to control the dissolution rate of magnesia in the reaction. Eubank ${ }^{13)}$ believes that after calcination at a high temperature of $1300{ }^{\circ} \mathrm{C}$, magnesia can significantly reduce the porosity of the particles and increase the particle size, thereby reducing the solubility of magnesia in water. Wagh and Jeong ${ }^{14)}$ conducted related experiments and found that after magnesia was calcined at $1300^{\circ} \mathrm{C}$ for $3 \mathrm{~h}$, the powder would agglomerate, the specific surface area decreased from 33.73 to $0.34 \mathrm{~m}^{2} / \mathrm{g}$, and the BET surface area was significantly reduced which is the main cause of the decrease in the solubility of magnesia. Due to the high energy consumption and high price of reburned magnesia powder, and the large consumption of high-quality magnesite resources, which hinders its large-scale promotion and application, reducing the sintering temperature of magnesia has become the research content of many scholars.

In this study, borax was mixed into light-burned magnesia (LBM), and the mixture was calcined at $1000-1200^{\circ} \mathrm{C}$ to obtain magnesia. Mixing the obtained $\mathrm{MgO}$ with $40 \%$ silica fume and add potassium monohydrogen phosphate solution to prepare magnesium phosphosilicate cement (MPSC). To explore the effect of different active $\mathrm{MgO}$ on MPSC cement by compressive strengths, X-ray diffraction (XRD), scanning electron microscope (SEM), energy dispersive spectrometer (EDS), mercury intrusion porosimetry (MIP) and Hydration heat release rate.

\section{Raw materials and experimental process}

\subsection{Raw materials}

(1) Magnesium oxide. The magnesium oxide used in this study is obtained by calcining magnesite (from Dashiqiao, Liaoning Province, China) at $750-850^{\circ} \mathrm{C}$. The chemical composition of LBM is shown in Table $\mathbf{1 .}$

(2) Light Silica Fume. The light SF, industrial grade, used in this experiment is produced by the Lingshou County Aotai Mineral Products Processing Factory which chemical composition is shown in the Table 2.

(3) Potassium Phosphate Dibasic. The analytical pure Potassium Phosphate Dibasic $\left(\mathrm{K}_{2} \mathrm{HPO}_{4} \cdot 3 \mathrm{H}_{2} \mathrm{O}\right)$ used in this experiment was produced by Hongyan Reagent Factory in Hedong District, Tianjin, where its technology index is shown in Table 3.

(4) Borax. The $\mathrm{Na}_{2} \mathrm{~B}_{4} \mathrm{O}_{7} \cdot 10 \mathrm{H}_{2} \mathrm{O}$ (abbreviated as B) used in this study is analytically pure producing from Chengdu Kelong Chemical Co., Ltd. The technology index is shown in Table 4.

Table 1. Chemical composition of LBM

\begin{tabular}{cccccccc}
\hline Component & $\mathrm{MgO}$ & $\mathrm{CaO}$ & $\mathrm{SiO}_{2}$ & $\mathrm{Al}_{2} \mathrm{O}_{3}$ & $\mathrm{Fe}_{2} \mathrm{O}_{3}$ & $\mathrm{CO}_{2}$ & $\mathrm{LL}$ \\
\hline Mass fraction (wt.\%) & 83.00 & 1.59 & 2.92 & 0.21 & 0.22 & 11.60 & 0.46
\end{tabular}

Table 2. Chemical composition of Light Silica Fume

$\begin{array}{llllllll}\text { Component } & \mathrm{SiO}_{2} & \mathrm{CaO} & \mathrm{MgO} & \mathrm{Al}_{2} \mathrm{O}_{3} & \mathrm{Fe}_{2} \mathrm{O}_{3} & \mathrm{CO}_{2} & \mathrm{LL}\end{array}$

\begin{tabular}{llllllll}
\hline Mass fraction (wt.\%) & 83.90 & 0.79 & 3.90 & 0.28 & 2.50 & 4.64 & 3.99
\end{tabular}

\subsection{Preparation of magnesia with different reactivities}

The LBM powder and a certain amount of borax are ball milled in a planetary ball mill with a speed of $300 \mathrm{rpm}$ for $15 \mathrm{~min}$, and the amount of borax introduced is $5 \%$ of the mass of magnesium oxide. To obtain different activity of magnesia, these mixed powders was calcined in a muffle furnace $\left(\mathrm{GWL}-1200^{\circ} \mathrm{C}\right)$ at temperatures ranging from 1000 to $1200^{\circ} \mathrm{C}$ for $2 \mathrm{~h}$ with a heating rate of $5^{\circ} \mathrm{C} \cdot \mathrm{min}^{-1}$ while LBM powder without borax was set as a control group at different calcination temperatures.

\subsection{Preparation of the samples}

To prepare MPSC cement specimens, the $\mathrm{MgO}$ : $\mathrm{K}_{2} \mathrm{HPO}_{4} \cdot 3 \mathrm{H}_{2} \mathrm{O}$ mass ratio (M:P) was fixed at $2: 1$ and the water-cement ratio $(\mathrm{w} / \mathrm{c})$ are set to 0.2 . In the process of preparing the solution, the crystal water contained in $\mathrm{K}_{2} \mathrm{HPO}_{4} \cdot 3 \mathrm{H}_{2} \mathrm{O}$ is also taken into consideration. Firstly, $\mathrm{K}_{2} \mathrm{HPO}_{4} \cdot 3 \mathrm{H}_{2} \mathrm{O}$ was added to deionized water, and stir homogeneously at room temperature to prepare dipotassium hydrogen phosphate solution. Secondly, the magnesium oxide was mixed with its mass fraction of $40 \%$ silica fume, the mixture was mechanically stirred with the dipotassium hydrogen phosphate solution to form the MPSC cement paste. The prepared MPSC slurry was cast in a $20 \times 20 \times 20 \mathrm{~mm}^{3}$ steel mold and cured at $20 \pm 3{ }^{\circ} \mathrm{C}$ and $50 \pm 5 \%$ relative humidity (standard curing). Demold the specimen after $24 \mathrm{~h}$ and cure to the required age. In the control group, borax with $5 \%$ magnesia mass fraction was added to the prepared dipotassium hydrogen phosphate solution as an external admixture to prepare MPSC cement. The raw material ratio of samples is shown in Table 5.

(illustrative: $\mathrm{T}$ denoted the experimental group, the raw material of magnesia in this group is obtained by cocalcining with borax at elevated temperature. $\mathrm{C}$ denoted the experimental group, this group of cement samples are prepared from magnesia raw materials calcined without

Table 3. Chemical composition of $\mathrm{K}_{2} \mathrm{HPO}_{4} \cdot 3 \mathrm{H}_{2} \mathrm{O}$

\begin{tabular}{ccccc}
\hline Component & $\mathrm{K}_{2} \mathrm{HPO}_{4} \cdot 3 \mathrm{H}_{2} \mathrm{O}$ & $\begin{array}{c}\text { Water } \\
\text { insoluble }\end{array}$ & Sulfate & $\mathrm{PH}$ \\
\hline Mass fraction (wt.\%) & $\geqslant 99.0$ & $\leqslant 0.01$ & $\leqslant 0.01$ & $8.9-9.4$ \\
\hline
\end{tabular}

Table 4. Chemical composition of $\mathrm{Na}_{2} \mathrm{~B}_{4} \mathrm{O}_{7} \cdot 10 \mathrm{H}_{2} \mathrm{O}$

\begin{tabular}{cccc}
\hline Component & $\mathrm{Na}_{2} \mathrm{~B}_{4} \mathrm{O}_{7} \cdot 10 \mathrm{H}_{2} \mathrm{O}$ & $\begin{array}{c}\text { Hydrochloric acid } \\
\text { insoluble matter }\end{array}$ & Sulfate \\
\hline Mass fraction (wt.\%) & $\geqslant 99.5$ & $\leqslant 0.01$ & $\leqslant 0.01$ \\
\hline
\end{tabular}

Table 5. The raw material ratio of samples

\begin{tabular}{ccccc}
\hline Specimens & $\begin{array}{c}\text { Mass ratio } \\
\text { (M:P) }\end{array}$ & $\begin{array}{c}\text { Water-cement } \\
\text { ratio }\end{array}$ & $\begin{array}{c}\text { Mixing ratio } \\
\text { (Light SF:MgO) }\end{array}$ & $\begin{array}{c}\text { Mass ratio } \\
\text { (Borax:MgO) }\end{array}$ \\
\hline $\mathrm{T} 1000$ & 2 & 0.2 & $40 \%$ & $0 \%$ \\
$\mathrm{~T} 1100$ & 2 & 0.2 & $40 \%$ & $0 \%$ \\
$\mathrm{~T} 1200$ & 2 & 0.2 & $40 \%$ & $0 \%$ \\
$\mathrm{C} 1000$ & 2 & 0.2 & $40 \%$ & $5 \%$ \\
$\mathrm{C} 1100$ & 2 & 0.2 & $40 \%$ & $5 \%$ \\
$\mathrm{C} 1200$ & 2 & 0.2 & $40 \%$ & $5 \%$ \\
\hline
\end{tabular}


borax, and $5 \%$ borax is added in the cement mixing process. $1000,1100,1200$ denote the calcination temperature of magnesia raw materials. For example, T1000 represent the specimen is prepared by the $\mathrm{MgO}$ calcined together with its mass fraction of $5 \%$ borax at $1000{ }^{\circ} \mathrm{C}$, the percentage of borax added during cement mixing is 0 .)

\subsection{Specimen analysis}

(1) Setting time: since the interval between the initial setting time and the final setting time of MPC cement is noticeably short, the initial setting time will be measured as the setting time in this experiment. The setting time of MPSC cement was measured according to the China national standard protocol GB/T1346-2011 by Vicat apparatus.

(2) Compressive strength: the compressive strength of MPSC cement was determined according to the GB1752007 testing standard. After curing 1, 3, 7 and 28 days, the compressive strength of MPSC cement was measured by testing machine with the maximum force of $300 \mathrm{kN}$ at a constant loading rate of $2.4 \mathrm{kN} \cdot \mathrm{s}^{-1}$.

(3) XRD: to determine the crystal phase composition of MPSC cement, the specimen cured to the required age was ground into phase powder (D90 $<35 \mu \mathrm{m}$ ) by using agate mortar before testing. Secondly, the specimens were analyzed on an X-ray diffractometer (D/max-2500PC, Rigaku Corporation, Tokyo, Japan) with the acceleration voltage was set to $30 \mathrm{kV}$ and the scan area ( $2 \theta$ range) was 10 to 70 degrees. Finally, the data were analyzed by "Highscore Plus" software to determine the type of the product.

(4) SEM: the microstructures of the samples were characterized by scanning electron microscopy (EM-30 Plus, COXEM CO., LTD., Daejeon, South Korea) after gold coating by Sputter Coater (ETD2000).

(5) EDS: EDS equipment (AZtecOne Xplore compact 30) used in this experiment was produced by Oxford instrument plc to determine the element content in samples.

(6) Hydration heat release rate: the hydration heat release rate of MPSC cement samples were tested by Calmetrix-I-Cal 4000HPC four-channel isothermal calorimeter (Calmetrix-4000HPC, Calmetrix Inc., Boston, Massachusetts, USA) at $20^{\circ} \mathrm{C}$.

(7) MIP test: the porosity and pore distribution of MPSC cement samples were measured using an automatic mercury porosimeter (AutoPore IV 9500, Micromeritics, Norcross, Georgia, USA) with the maximum pressure is 33,000 pounds $(228 \mathrm{MPa})$, the aperture measuring range is 50 angstroms-1000 microns.

\section{Results and discussion}

\subsection{Characterization of magnesia with differ- ent reactivities}

Table 6 shows the characterization parameters of magnesia obtained by calcining light burnt powder at different temperatures. The activity of magnesium oxide was measured by the hydration method of Dong et al. ${ }^{15)}$ Among them, due to the decomposition of $\mathrm{MgCO}_{3}$, compared with LBM, the activity of $1000^{\circ} \mathrm{C}$ (without B) has increased from 56.58 to $83.00 \%$. Figure 1 shows the XRD data of the above two $\mathrm{MgO}$ samples, the diffraction peaks of $\mathrm{MgCO}_{3}$ can be observed in LBM which cannot in another. This shows that $\mathrm{MgCO}_{3}$ decomposes in the heating process to produce new magnesium oxide, thereby increasing the activity of the powder, and as the temperature further increases, the reactivity of the powder decreases as the temperature increases.

Experimental data shows that the magnesium oxide powder prepared by calcining with borax has lower BET surface area and reactivity than that of without borax. With an addition of borax and calcinated at $1000^{\circ} \mathrm{C}$, the reactivity of powder decreases from 83.00 to $50.05 \%$, and the BET surface area decreases from 8.82 to $3.26 \mathrm{~m}^{2} / \mathrm{g}$. This indicates that when borax is added, magnesium oxide is sintered into large crystals, and the reactivity will be further reduced. This is confirmed in the SEM photos. Figure 2 show the SEM images of magnesia powder calcined at $1000^{\circ} \mathrm{C}$ with or without $\mathrm{B}$. In contrast, the crystal size of $1000^{\circ} \mathrm{C}$ (without $\mathrm{B}$ ) is relatively small, while that of $1000^{\circ} \mathrm{C}$ (with $5 \% \mathrm{~B}$ ) has a significant increase, which shows that borax increases the crystal size of magnesia during the calcination process.

Simultaneously, with an increase in temperature from 1000 to $1200^{\circ} \mathrm{C}$, the reactivity and BET surface area of $\mathrm{MgO}$ powder is continuously reduced. Soudée and Péra ${ }^{16)}$ pointed out that the crystal surface of magnesia is reorganized after high temperature calcination with the BET surface area decrease, and the defects are reduced. The

Table 6. Characterization parameters of calcined magnesia at different temperatures

\begin{tabular}{ccc}
\hline $\mathrm{MgO}$ & $\begin{array}{r}\text { BET surface area } \\
\left(\mathrm{m}^{2} / \mathrm{g}\right)\end{array}$ & $\begin{array}{c}\mathrm{MgO} \text { activity } \\
(\%)\end{array}$ \\
\hline LBM & 13.23 & 56.58 \\
$1000^{\circ} \mathrm{C}$ (with 5\% B) & 3.26 & 50.05 \\
$1100^{\circ} \mathrm{C}$ (with 5\% B) & 1.88 & 25.32 \\
$1200^{\circ} \mathrm{C}$ (with 5\% B) & 0.96 & 16.47 \\
$1000^{\circ} \mathrm{C}$ (without B) & 8.82 & 83.00 \\
$1100^{\circ} \mathrm{C}$ (without B) & 2.14 & 66.35 \\
$1200^{\circ} \mathrm{C}$ (without B) & 1.35 & 33.68 \\
\hline
\end{tabular}

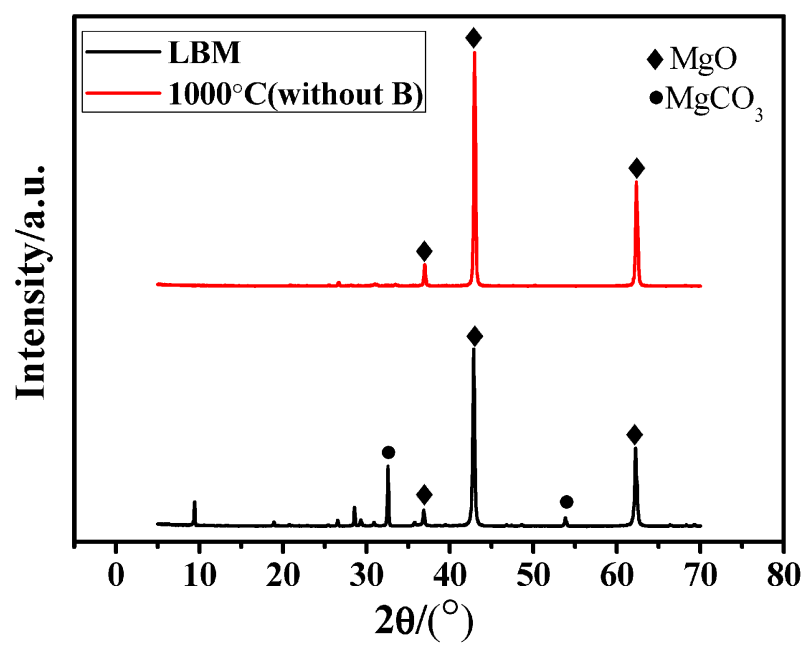

Fig. 1. XRD data of different magnesia samples. 


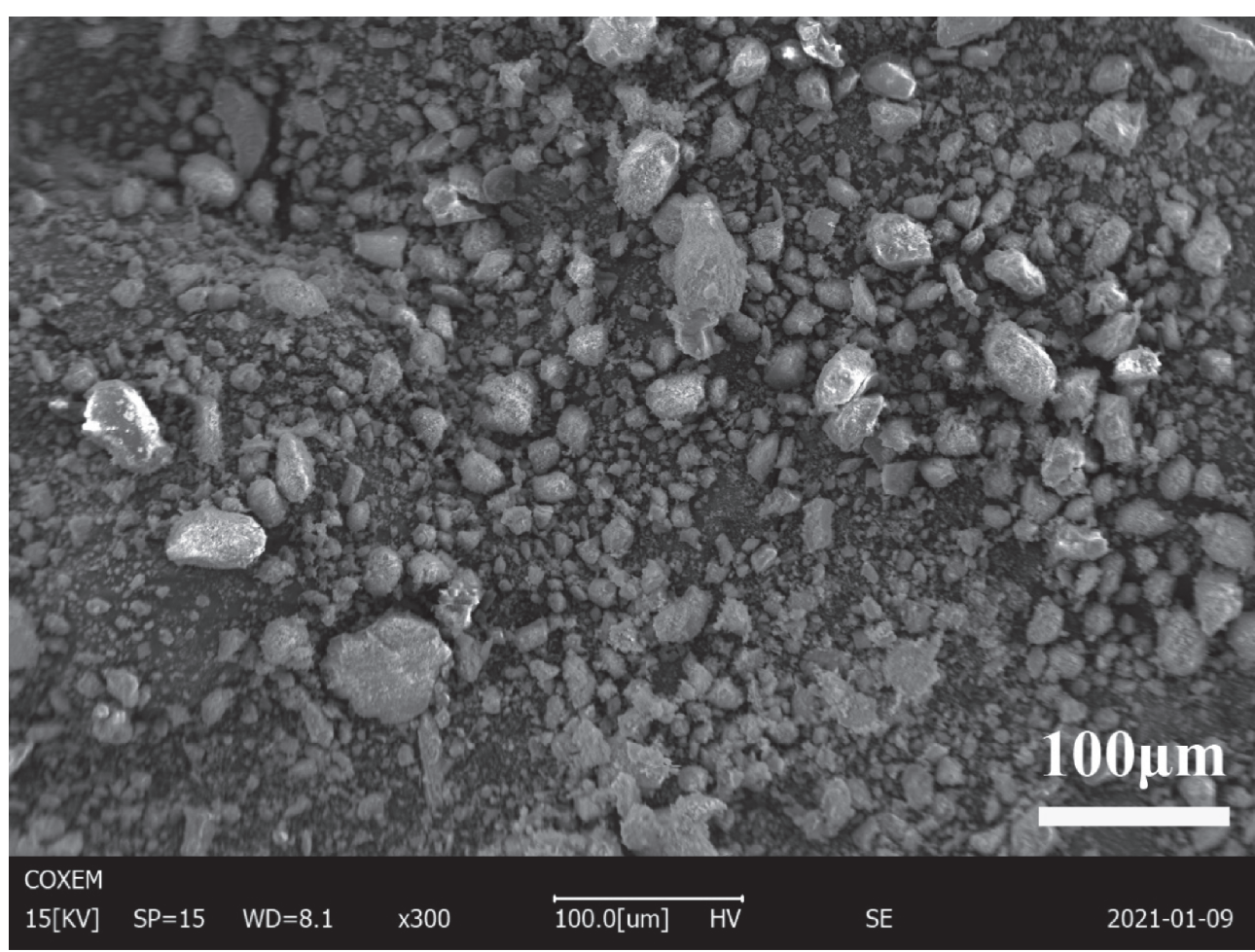

(a)

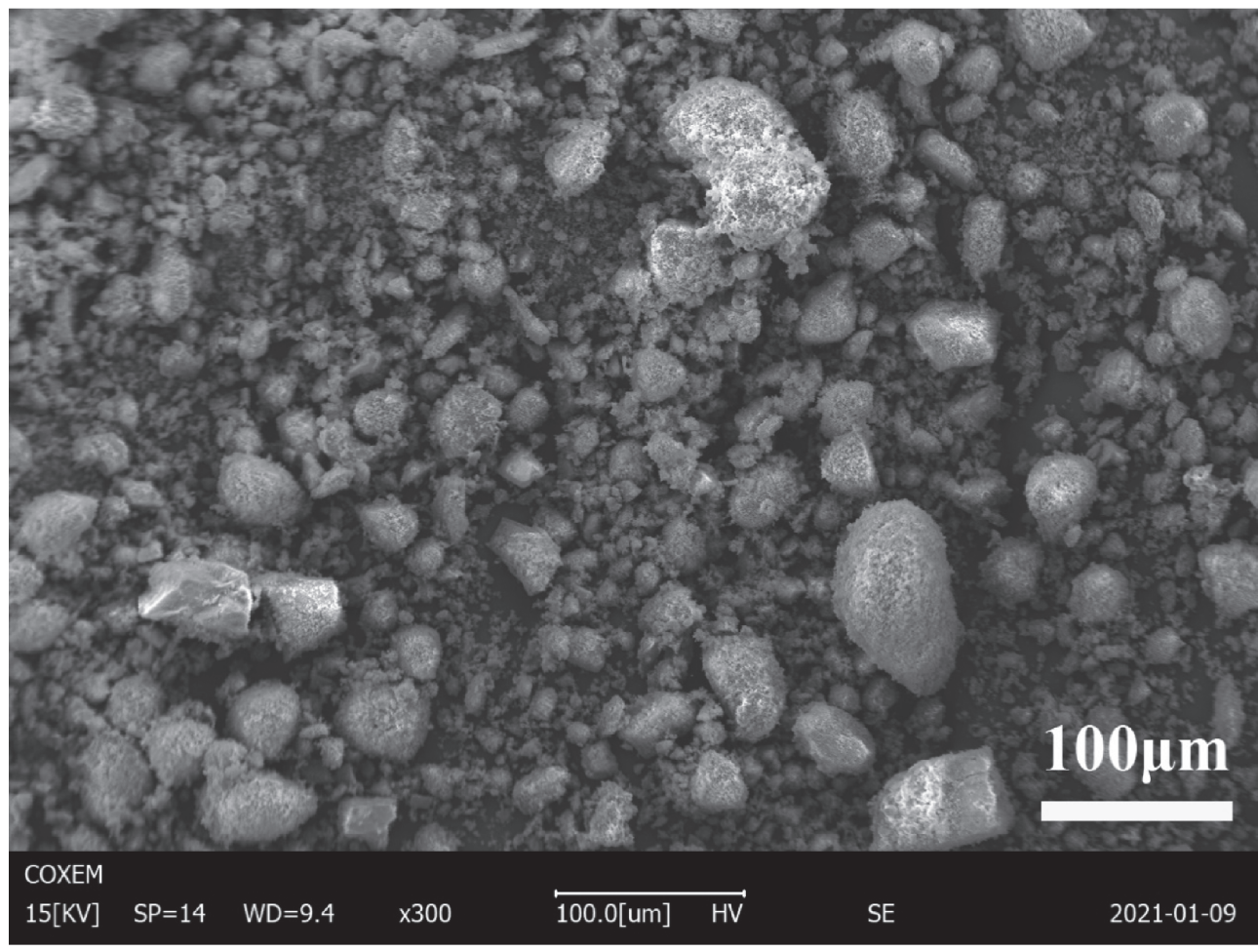

(b)

Fig. 2. SEM observation of raw material (a) for $1000^{\circ} \mathrm{C}$ (without B), and (b) for $1000^{\circ} \mathrm{C}$ (with $5 \%$ B).

higher the calcination temperature, the closer the BET surface area is to the theoretical calculation value with the reactivity of magnesia is lowest at this time, the setting time of MPC cement is also longer.

\subsection{Setting time}

Figure 3 show the influence rule of reactivity of magnesia on the setting times of MPSC cement. Among them, the T1000 cement sample cannot be formed because it has 


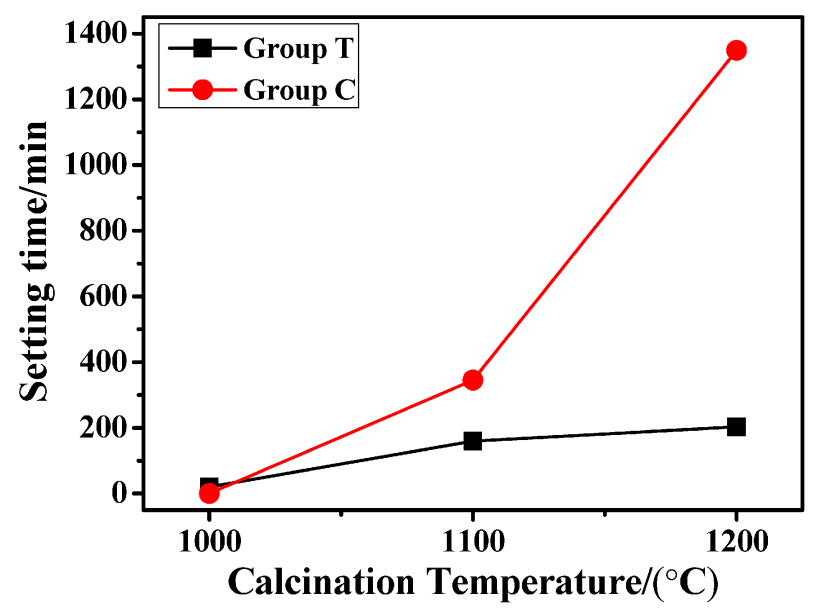

Fig. 3. Setting times of Group $\mathrm{T}$ and $\mathrm{C}$ at different temperature.

hardened during mixing process, so the setting time is recorded as $0 \mathrm{~min}$. It can be seen from Fig. 3 that the setting time gradually increase with the rise in temperature, and the setting time of cement samples of T1000, T1100 and T1200 reached 20, 160 and 203 min, respectively. At 1100 and $1200^{\circ} \mathrm{C}$, the setting time of Group $\mathrm{C}$ is longer than that of Group $\mathrm{T}$, but the result is the opposite at $1000^{\circ} \mathrm{C}$. This is the result of the combined effect of the reactivity of magnesia and the admixture borax, Yang ${ }^{17)}$ found that if the phosphorus content remains fixed, the setting time of MPC cement increases linearly with the increase of the admixture borax. Simultaneously, at the same borax content, the cement reaction can be accelerated by increasing the reactivity of magnesia. This explains why the setting time of Group C is shorter than that of Group T at $1000^{\circ} \mathrm{C}$, while it is longer at other temperatures.

Figure 4 shows the hydration heat release rate of MPSC cements. With the increase of the BET surface area of magnesia, the early heating rate of MPSC slurry increase. Besides, the time for MPSC slurry to reach the setting temperature and the maximum temperature will be shortened, which are consistent with the Yang's reports. ${ }^{18)}$ Although at 1100 and $1200{ }^{\circ} \mathrm{C}$, the reactivity and BET surface area of magnesia of group $\mathrm{C}$ are higher than those of group $\mathrm{T}$, the first exothermic peak is lower than that of group $\mathrm{T}$. This shows that the incorporation of borax reduces the exothermic peak in the cement reaction. In C1000, the retarding effect of borax is not obvious, which is presumed to be the reason for the high reactivity and BET surface area of its magnesia raw materials.

\subsection{Compressive strength}

Figure 5 shows the compressive strength development of different MPSC cement samples. Among these samples, the strength of $\mathrm{C} 1000$ cannot be tested owing to it cannot be formed. It is observed that the early strength is positively related to the reactivity and BET surface area of magnesia. Although the raw material of magnesia has higher reactivity and BET surface area, the early strength of C1100 and C1200 do not follow known laws. For example, the 1-day strengths of C1100 and C1200 are 3.2 and $0 \mathrm{Mpa}$,

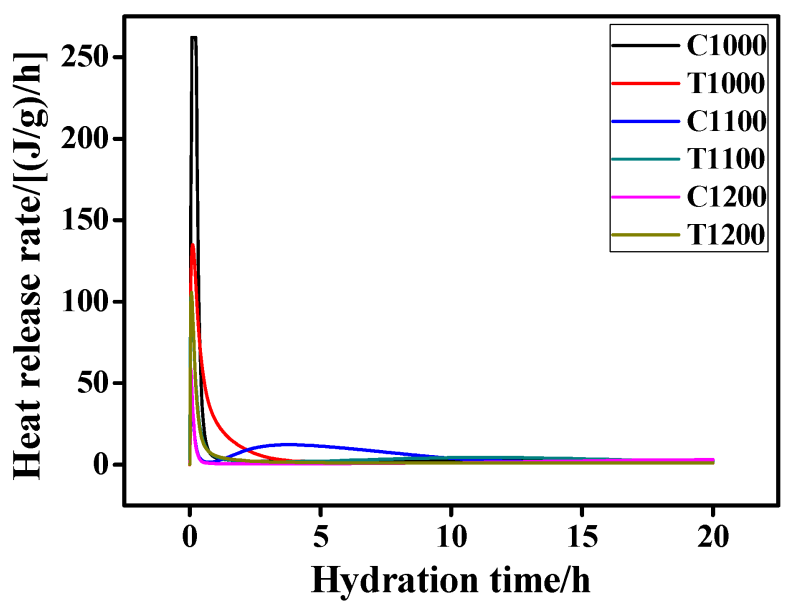

(a) Hydration time range from $0 \mathrm{~h}$ to $20 \mathrm{~h}$

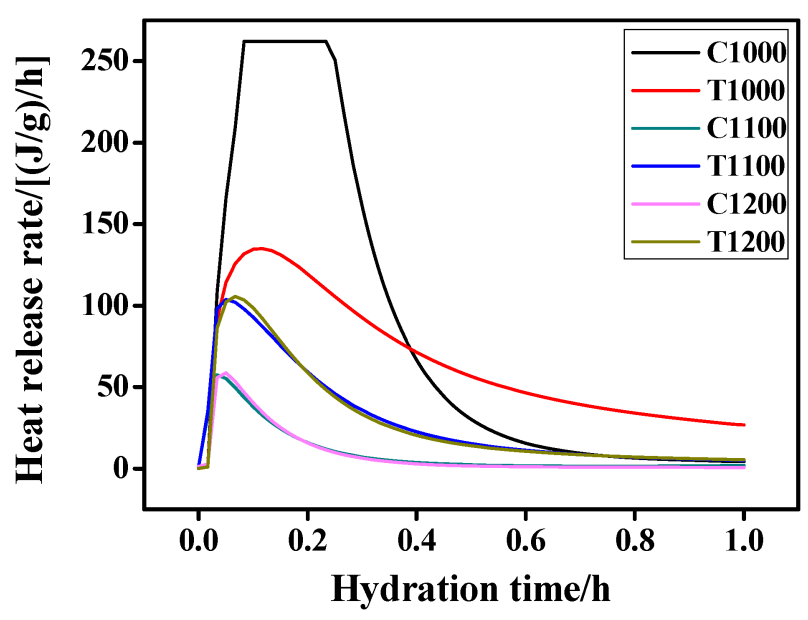

(b) Hydration time range from $0 \mathrm{~h}$ to $\mathrm{lh}$

Fig. 4. Hydration heat-release rate of different MPSC cements.

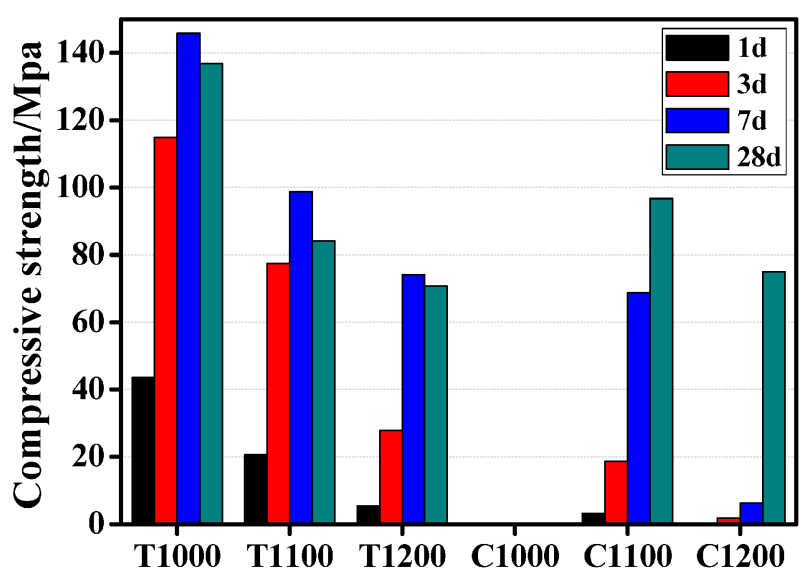

Fig. 5. Compressive strength of MPSC cement prepared using magnesia with different reactivity.

while T1100 and T1200 reach 20.6 and 5.5 Mpa, respectively. Borax added during cement mixing can be one of important cause for this phenomenon (Section 3.2).

As shown in Fig. 5, the strength of MPSC cement samples decreases with increasing calcination temperature. 


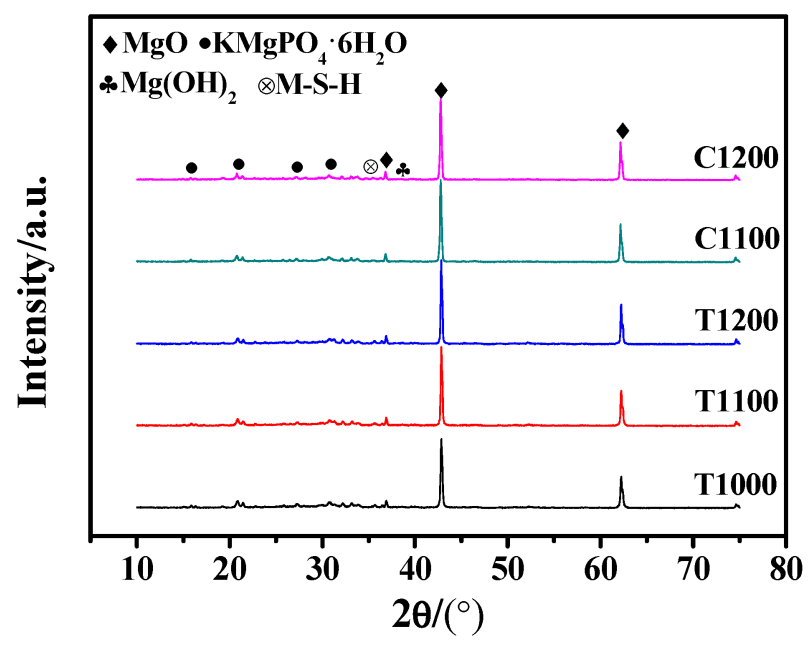

(a) Angular range from $10^{\circ}$ to $70^{\circ}$

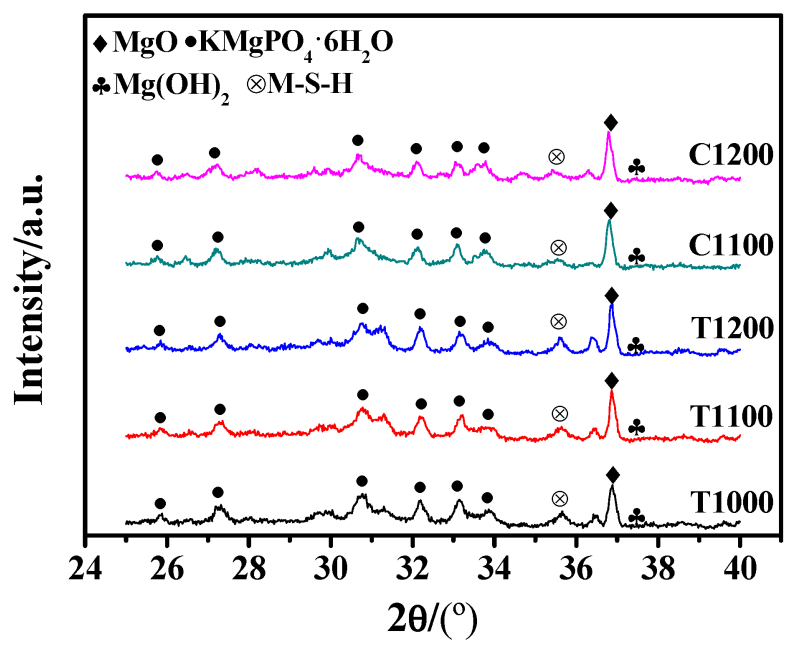

(b) Angular range from $25^{\circ}$ to $40^{\circ}$

Fig. 6. XRD pattern of MPSC cement after curing 28 days.

Due to the lower hydration rate, the 1-day strength of T1200 is only $5.5 \mathrm{Mpa}$, while that of T1000 reaches 43.5 Mpa. Therefore, in order to prepare MPSC cement with high early strength, it is necessary to appropriately control the calcination temperature of magnesia. Although the early strengths of C1100 and C1200 are not high, their 28-day strength has a large increase, which is equivalent to the strength of T1100 and T1200 in the same period, indicating that borax has a significant effect on the early strength, but has a small effect on the strength of 28 days.

\subsection{XRD analyses}

Figure 6 plots the XRD pattern of MPSC cement after 28 days of curing. In Fig. 6(a), strong characteristic peaks of magnesium oxide can be observed in each sample, as marked at 42.9 and $62.3^{\circ}$. Due to the excessive magnesia content in the entire reaction system, there is a large amount of unreacted magnesia in the cement sample, and these magnesia also act as a framework. In T1000, T1100 and T1200, the intensities of the characteristic peak of magnesia continues to increase. Indicating that as the calcination temperature increases, the content of residual unreacted magnesia in the cement will also increase, which leads to a decrease in strength. Figure 6(b) is an enlarged drawing, where the weak characteristic peaks of brucite $\left[\mathrm{Mg}(\mathrm{OH})_{2}\right]$ can be observed. It is an intermediate product formed during the reaction of magnesia. $\left.{ }^{19}\right) \mathrm{The}^{\mathrm{SiO}} \mathrm{in}_{2}$ in the silica fume may react with $\mathrm{Mg}(\mathrm{OH})_{2}$ to form hydrous magnesium silicate, thereby inhibiting the formation of $\mathrm{Mg}(\mathrm{OH})_{2}$. In the potassium MPC system, the hydration product is relatively single, Ding and Wagh et al. ${ }^{20), 21)}$ analyzed their hydration products by a series of characterization methods such as XRD, DTA, FT-IR, and deduced that the main composition is $\mathrm{MgKPO}_{4} \cdot 6 \mathrm{H}_{2} \mathrm{O}(\mathrm{MKP})$. The characteristic peak that represented $\mathrm{MgKPO}_{4} \cdot 6 \mathrm{H}_{2} \mathrm{O}$ could also be found in patterns obviously. It is observed that the peaks of MKP do not change significantly at different calcination temperatures, showing that the reactivity of magnesia may not have a significant effect on the formation of MKP. Liu et al. ${ }^{22)}$ found that after introducing nano-silica into MPC cement, a new characteristic peak was generated in pattern, which represented the newly formed magnesium silicate (M-S-H). The M-S-H phases are marked in Fig. 6(b) which had low quantity and not clear to observed. In addition, no crystalline substance containing boron is found in all XRD patterns. Therefore, it is speculated that boron exists in an amorphous form.

\subsection{SEM-EDS analysis}

Figure 7 shows the SEM images of different MPSC cements after 28 days of curing. As mentioned by Chau et al., ${ }^{23)}$ with an $\mathrm{M} / \mathrm{P}$ ratio as low as mere 2, the hexahydrate would grow into slender acicular polycrystals with large aspect ratio. However, needle-like MKP crystals are difficult to find in the pictures, it is speculated that they are buried by a large number of magnesia particles and $\mathrm{M}$ $\mathrm{S}-\mathrm{H}$ gel. In all microphotographs, unreacted magnesia particles of tiny round shape could be found, and the residual magnesia particles on the sample surface increase with the increase of temperature. The microstructure of MPSC cement became loose and more voids appeared after increasing the calcination temperature from 1000 to $1200{ }^{\circ} \mathrm{C}$. For example, the surface of T1000 is flat and dense, while that of T1200 is uneven and more voids could be observed, with a large amount of unreacted magnesia particles attached to the surface. C1100 and C1200 also reflect the same trend. It shown that magnesia with high reactivity and small particle size can promote the compactness of cement matrix, and smaller magnesia particles are easier to fill in the voids, reducing the porosity, thereby increasing the strength of the cement, which is also consistent with the results of mechanical property that discussed before.

Figure 8 displays the EDS result on Spot and Map of T1000 after curing 28 days. Tested the spherical crystal in the picture and named it Spot. The results show in Fig. 8(b) that the highest content of $\mathrm{Si}$ in Spot indicates that the substance is $\mathrm{SiO}_{2}$. Besides, $\mathrm{Mg}, \mathrm{K}$, and $\mathrm{P}$ were also 


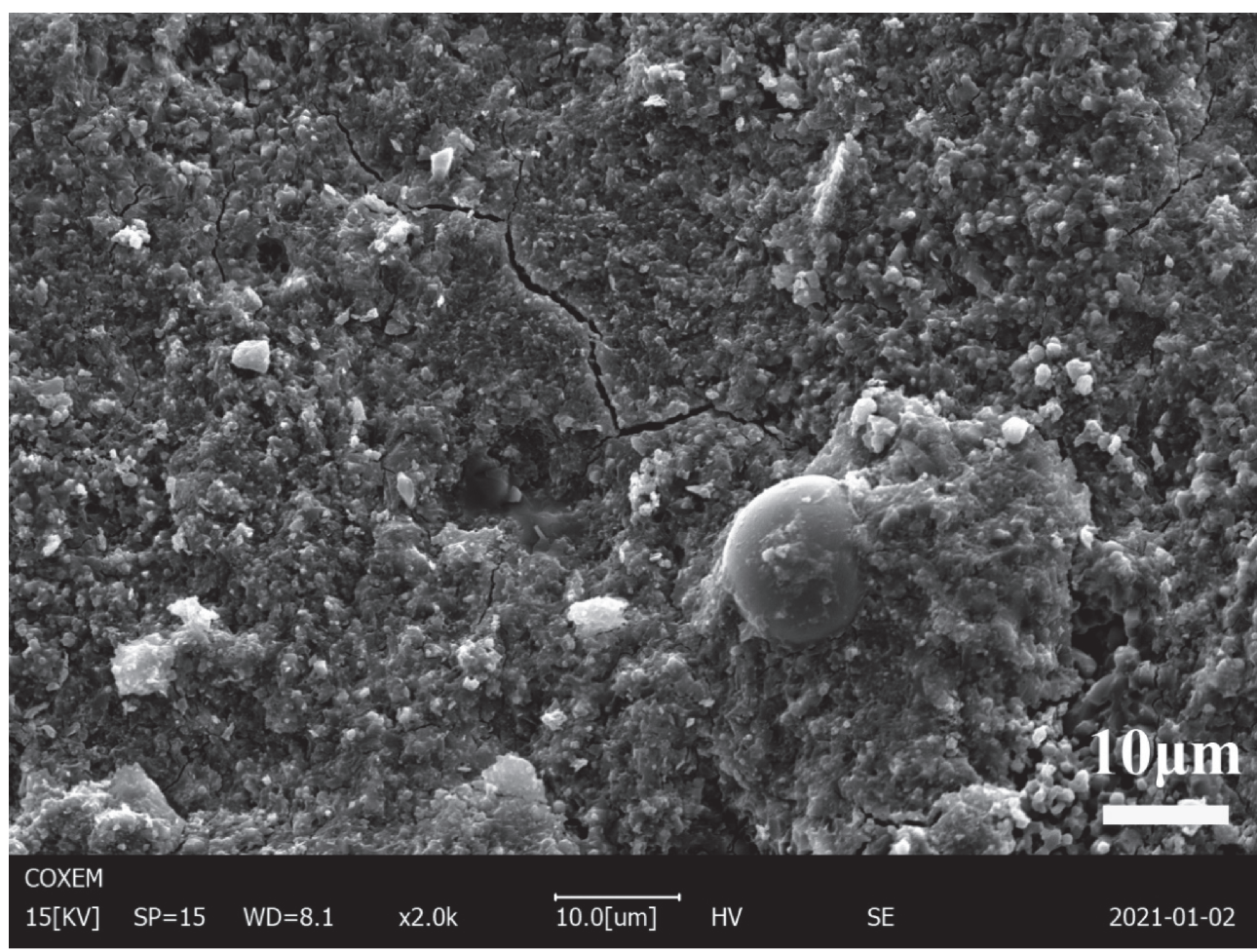

(a) T1000 after curing 28 days

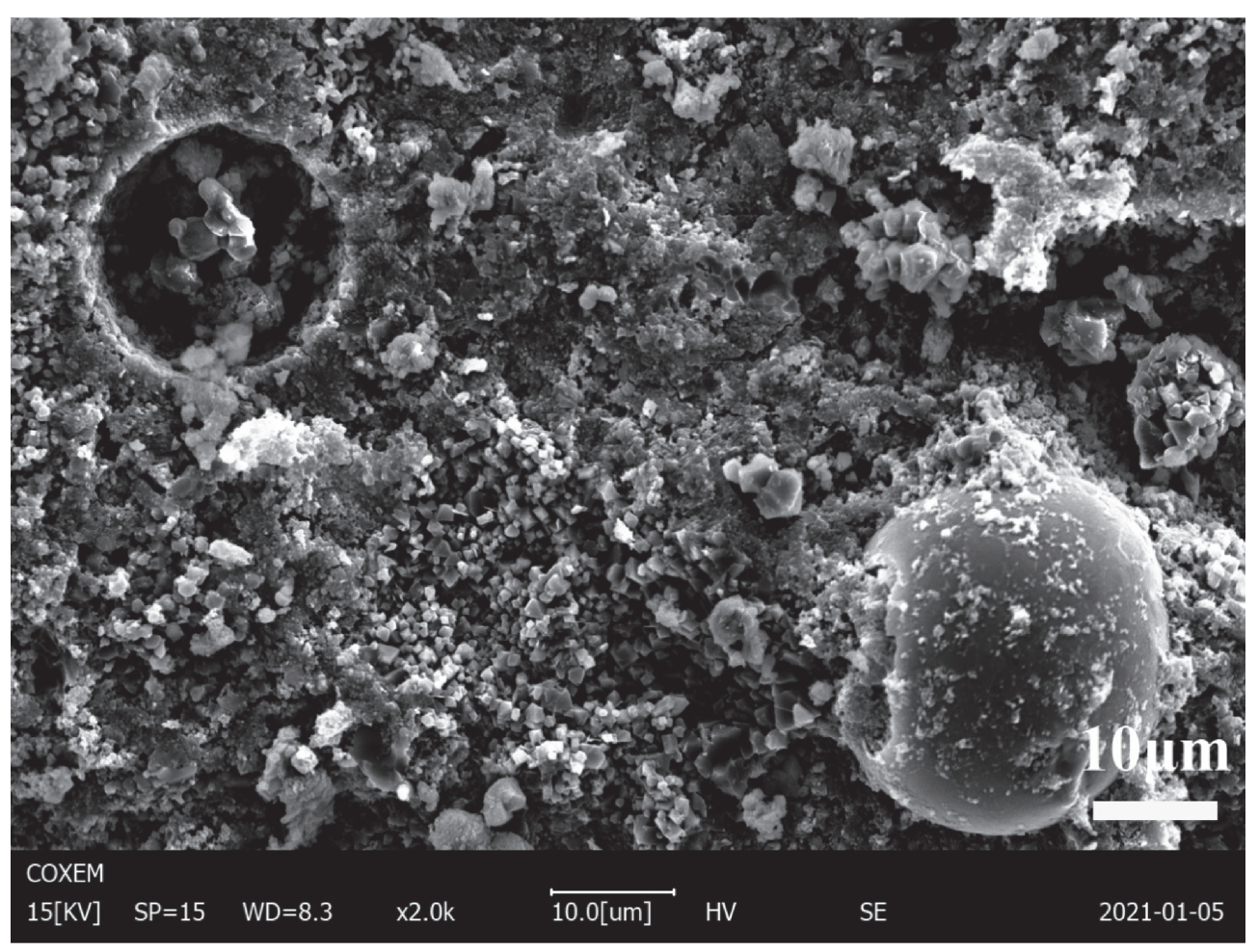

(b)T1100 after curing 28 days

Fig. 7. Continued on next page. 


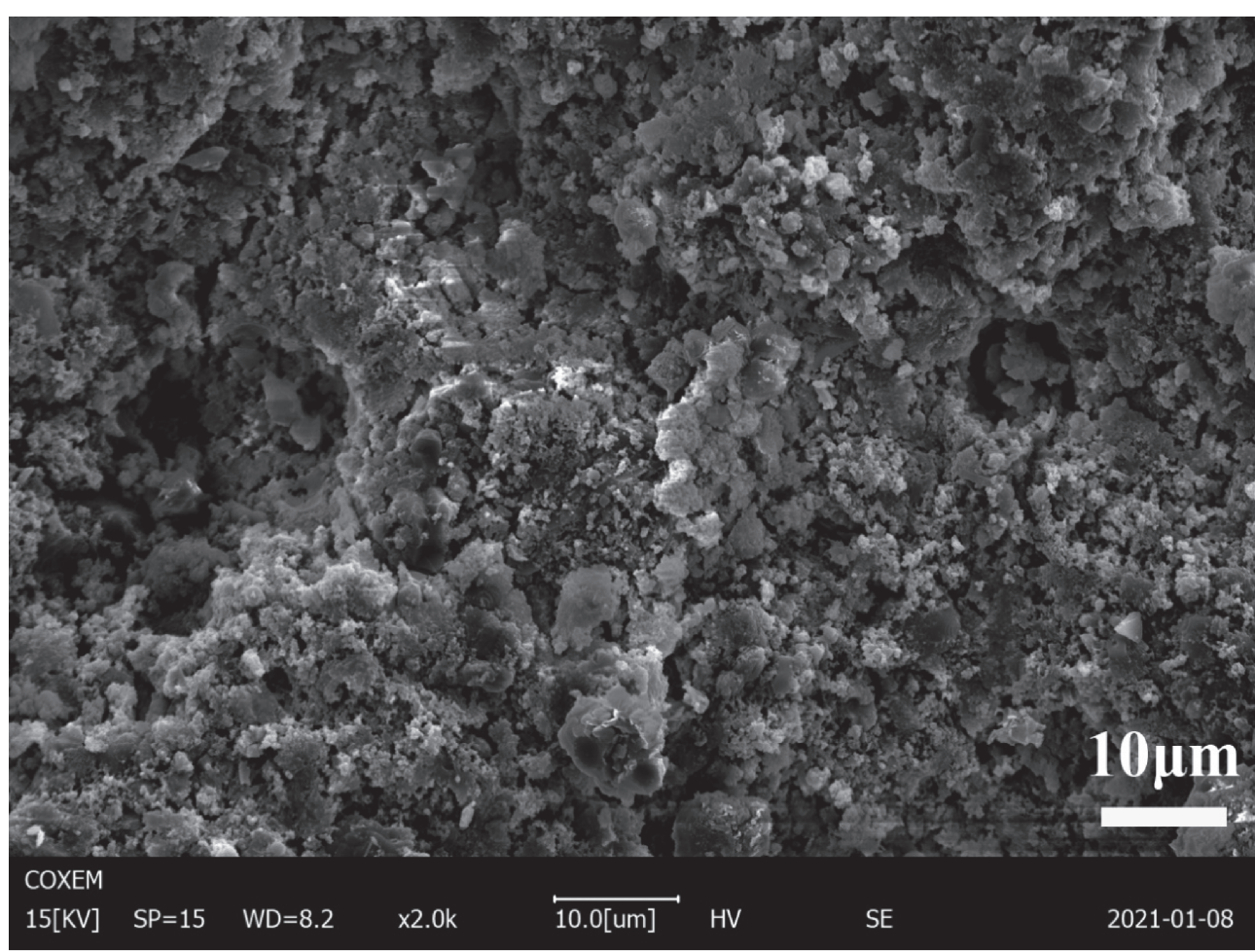

(c)T1200 after curing 28 days

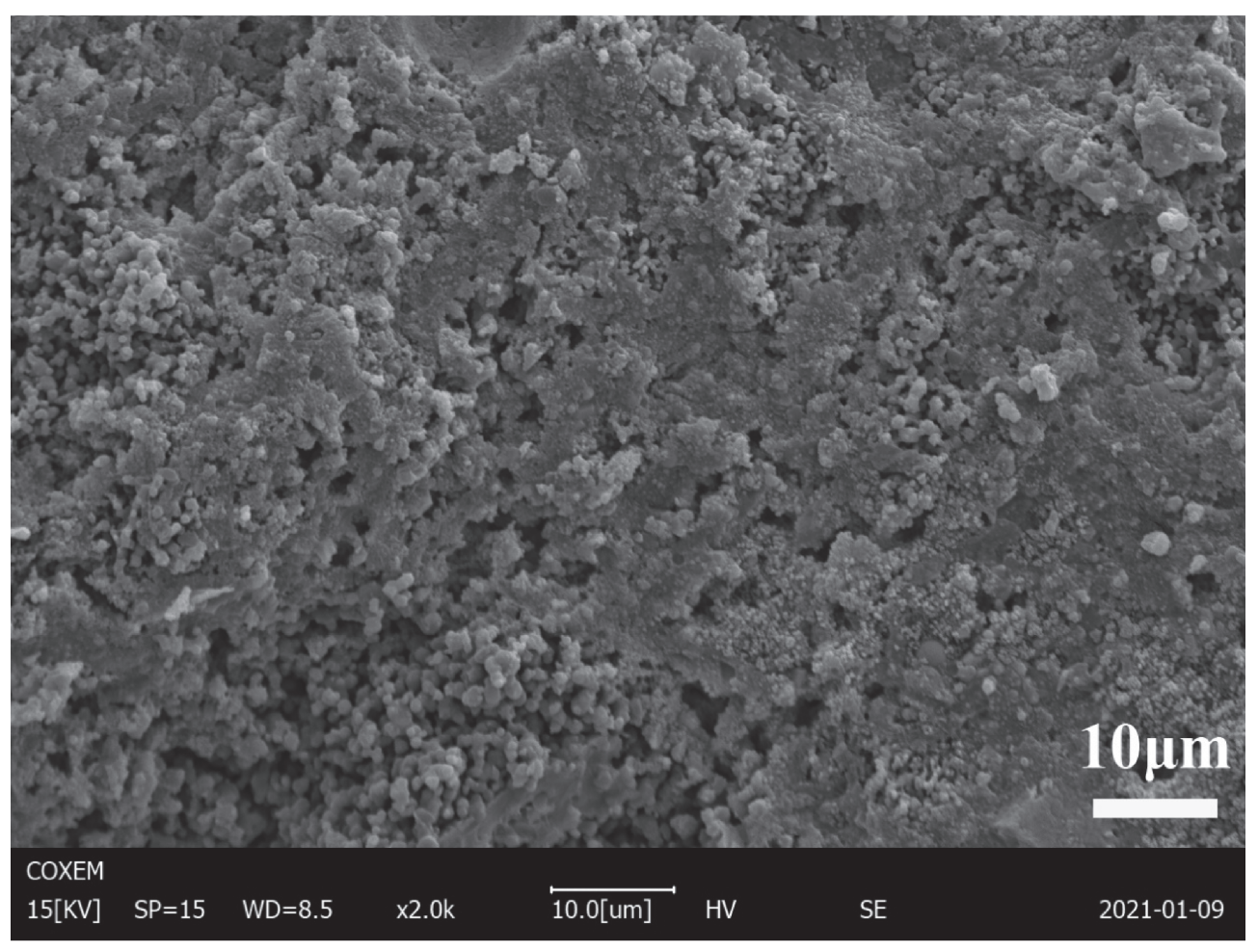

(d)C1100 after curing 28 days

Fig. 7. Continued on next page. 


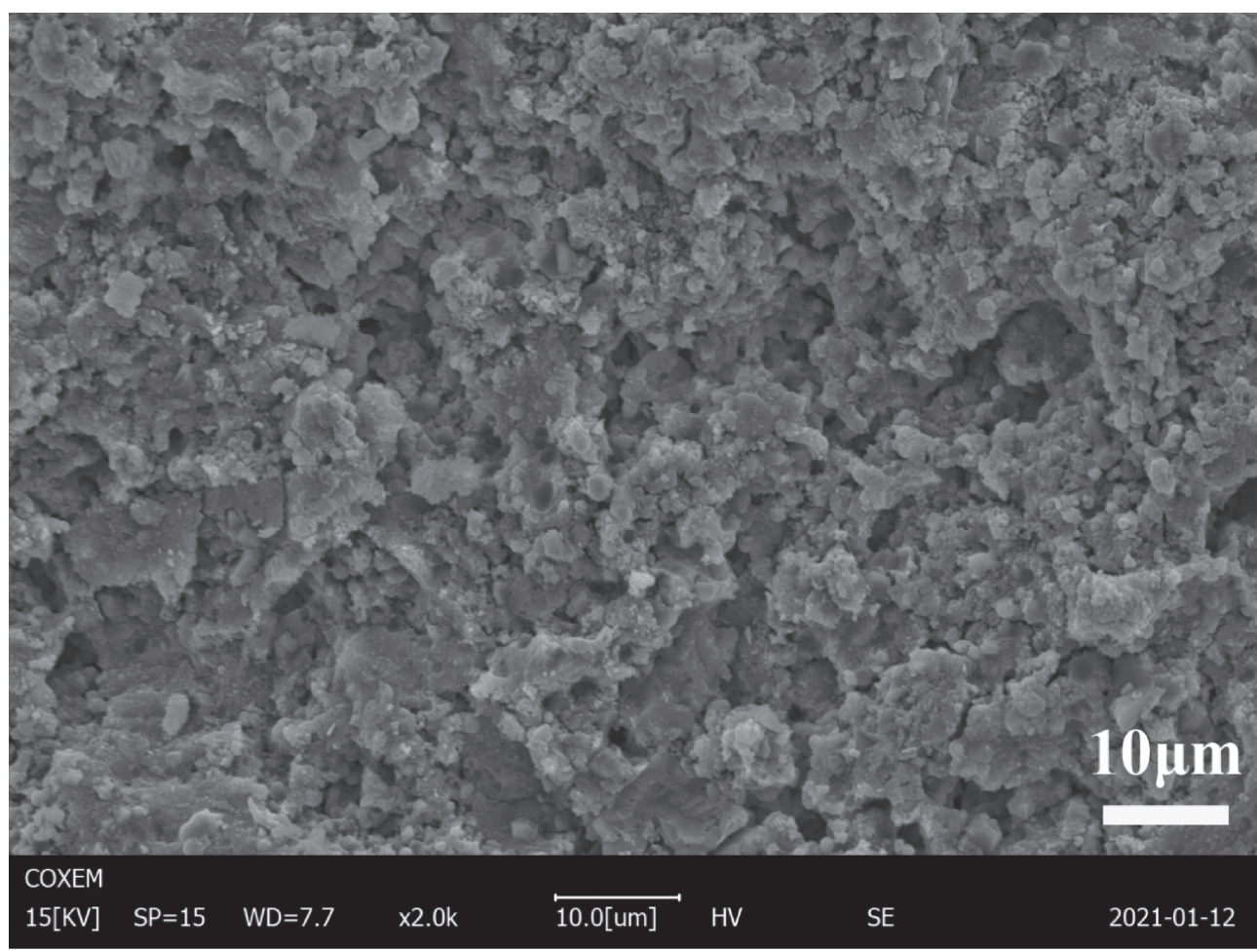

(e)C1200 after curing 28 days

Fig. 7. The SEM images of different MPSC cements.

detected, and $\mathrm{SiO}_{2}$ crystals were observed to be embedded in the cement matrix. This was attributed to the fact that $\mathrm{MgO}$ and MKP may adhere to the surface of the particles and the $\mathrm{SiO}_{2}$ did not completely react to form M-S-H gel. The distribution of elements in a small flat area named Map in Fig. 8(a) is analyzed, and the analysis results are displayed in Fig. 8(c). Magnesium is widely distributed and highlighted in Fig. 8(c), indicating that magnesia crystals that have not participated in the reaction are attached to the surface of this area. $\mathrm{Si}, \mathrm{P}$ and $\mathrm{K}$ are also distributed in this area, indicating that it is a mixture of M-S-H gel and MKP crystals.

\subsection{Pore structure}

According to current research, cement hydration products are closely related to the internal pore structure of cement paste. The mechanical properties of cement not only depend on the type and content of hydration products, but also restricted by the internal pores of the cement slurry. To further explain the influence of magnesia reactivity on the microstructure of MPSC cement, the cumulative porosity of the MPSC cement was shown in Fig. 9, and Table 7 lists the pore distribution of MPSC cement. It can be seen from Table 7 that the calcination temperature of magnesia has an effect on the average pore diameter of MPSC cement. For instance, the pore size of T1000 is $116.81 \mathrm{~nm}$, while that of T1100 and T1200 were 157.72 and $160.03 \mathrm{~nm}$, an increase of 35 and $37 \%$ respectively. Simultaneously, the higher the reactivity of the magnesia, the denser the microstructure of MPSC cement and the lower the porosity. For example, the porosity of T1200 is $26.47 \%$, which is approximately twice as that of $\mathrm{T} 1000$.

\section{Conclusion}

This study describes the effect of magnesia reactivity on the macroscopic properties and microstructure of MPSC cement. Based on the experimental results, the following conclusions are drawn:

(1) As the calcination temperature increases, the BET surface area of magnesia decreases, and the crystals are gradually sintered into large particles, so the reactivity also decreases.

(2) Adding $5 \%$ borax in the calcination process can further reduce the reactivity of magnesia. By comparison, the magnesia powder prepared in this way has a larger crystal size than the traditional method.

(3) The mechanical properties of MPSC cements prepared using different reactivity of magnesia are different. The MPSC cement have good early strength prepared by high reactive magnesia, but it also has the defect of too fast reaction time. As the reactivity of magnesia decreases and the setting time increases, the mechanical properties of cement also decrease. Therefore, in order to prepare a MPSC cement with a suitable setting time and higher early strength, there is a most suitable magnesium oxide activity parameter.

(4) The higher the reactivity of magnesia, the lower the porosity of the prepared MPSC cement. The crystal size of highly reactive magnesium oxide is small, so it is easier to fill the gaps of the cement matrix to reduce the porosity. 


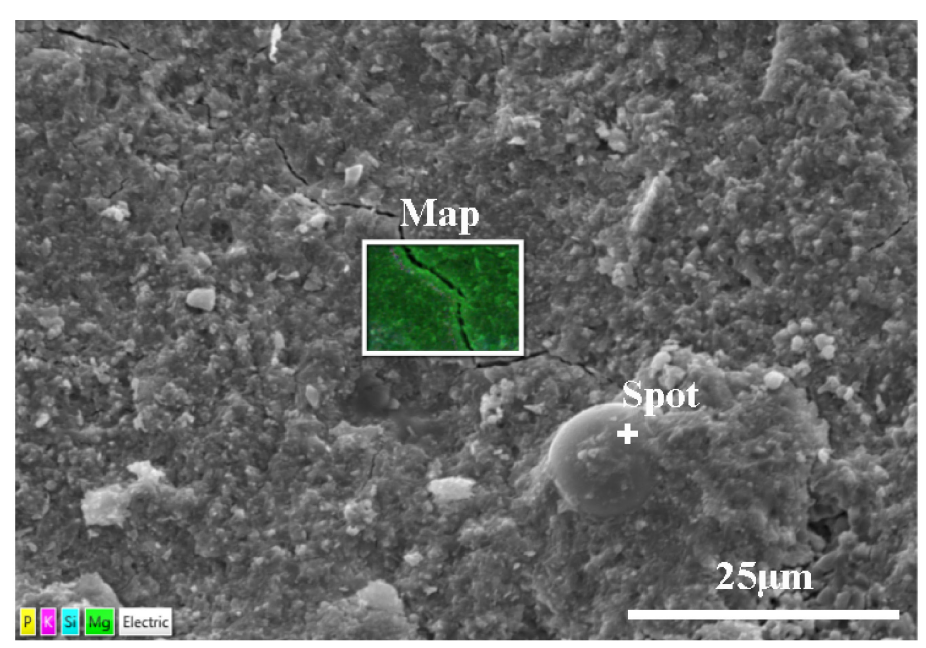

(a)The SEM image of T1000 after curing 28 days

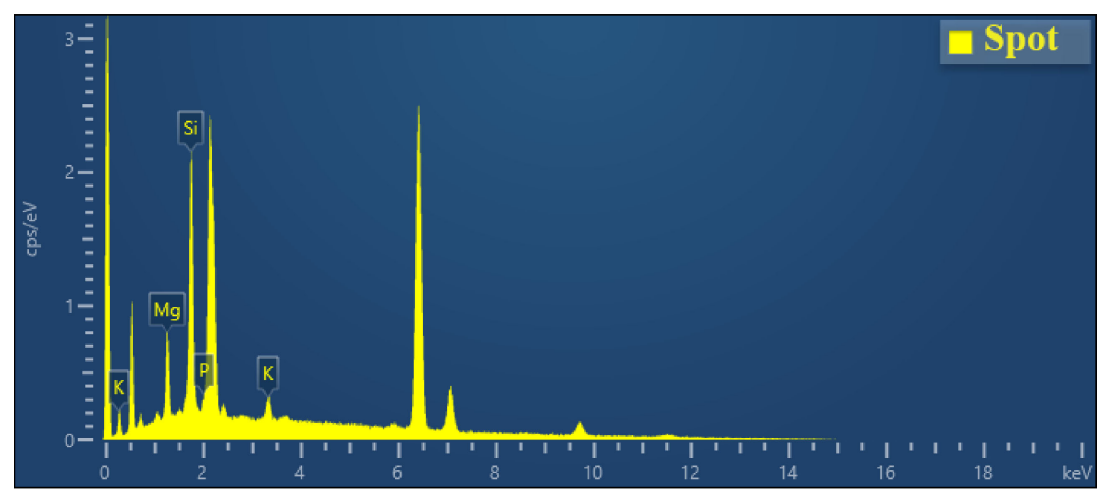

(b) The spectrum of Spot

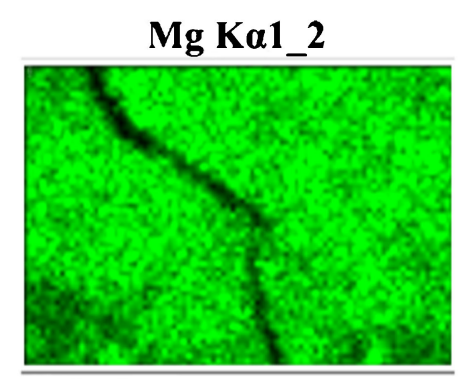

K Ka1
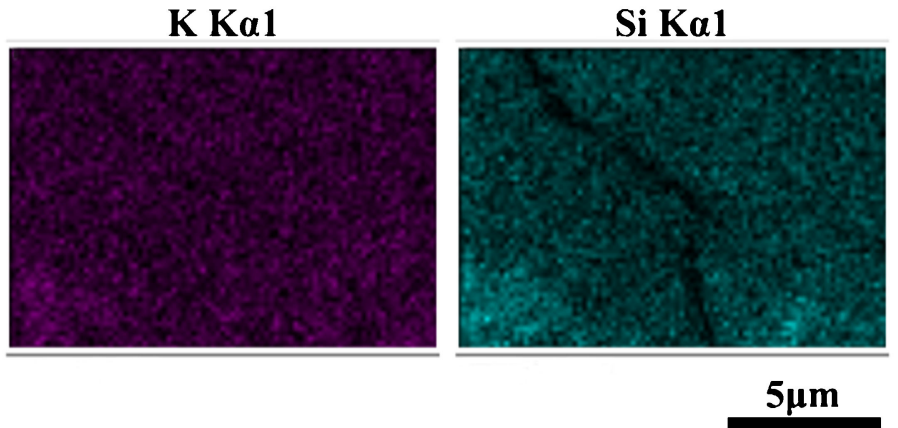

(c) The distribution of elements in Map

Fig. 8. The EDS result on Spot and Map of T1000 after curing 28 days. 


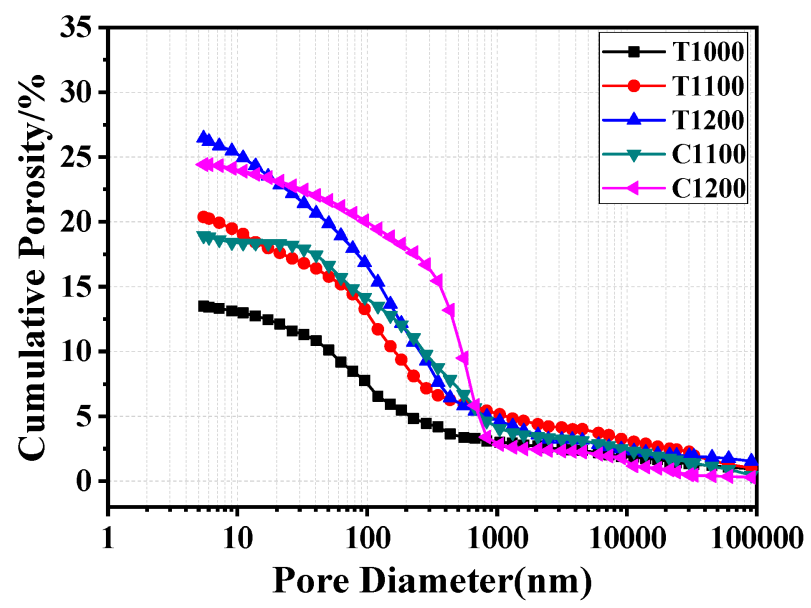

Fig. 9. Cumulative Porosity of MPSC cement after curing 28 days.

Table 7. Statistics of pore distribution of MPSC cement curing 28 days

\begin{tabular}{ccccc}
\hline Samples & $\begin{array}{c}\text { Average pore } \\
\text { diameter }(\mathrm{nm})\end{array}$ & $\begin{array}{c}\text { Porosity } \\
(\%)\end{array}$ & $\begin{array}{c}\leq 10 \mathrm{~nm} \\
(\%)\end{array}$ & $\begin{array}{c}\geq 10 \mathrm{~nm} \\
(\%)\end{array}$ \\
\hline $\mathrm{T} 1000$ & 116.81 & 13.49 & 3.78 & 96.22 \\
$\mathrm{~T} 1100$ & 157.72 & 20.36 & 5.71 & 94.29 \\
$\mathrm{~T} 1200$ & 160.03 & 26.47 & 5.79 & 94.21 \\
$\mathrm{C} 1100$ & 302.65 & 18.93 & 2.35 & 97.65 \\
$\mathrm{C} 1200$ & 466.17 & 24.37 & 2.90 & 97.10 \\
\hline
\end{tabular}

Simultaneously, it reacts with silica to form more amorphous M-S-H gels, which fill the voids and further reduce the porosity.

Acknowledgement This project is supported by the National Natural Science Foundation of China (Grant No. 52002202) and Western Light Project of Chinese Academy of Sciences, applied fundamental research project of Qinghai Province (Grant No. 2019-ZJ-7005) and the S\&T Foundation Platform of Qinghai Province (Grant No. 2018ZJ-T01).

\section{References}

1) E. M. Prosen, US Patent, 2152152 (1939).

2) R. F. Stierli, C. C. Tarver and J. M. Gaidis, US Patent,
3,960,580 (1976).

3) L. Lang, H. J. Duan and B. Chen, Constr. Build. Mater., 209, 95-104 (2019).

4) G. Mestres, F. S. Aguilera, N. Manzanares, S. Sauro, R. Osorio, M. Toledano and M.-P. Ginebra, Int. Endod. J., 47, 127-139 (2014).

5) P. Zhu, L. He, L. Qiu, A. H. Korayem, G. Li, J. W. Zhu, F. Collins, D. Li, W. H. Duan and M. C. Wang, Cement Concrete Comp., 58, 140-147 (2015).

6) B. Xu, B. Lothenbach, A. Leemann and F. Winnefeld, Cement Concrete Res., 108, 140-151 (2018). doi:10. 1016/j.cemconres.2018.03.013

7) S. Fan and B. Chen, Constr. Build. Mater., 65, 480-486 (2014). doi:10.1016/j.conbuildmat.2014.05

8) H. Ma, B. Xu and Z. Li, Cement Concrete Res., 65, 96104 (2014). doi:10.1016/j.cemconres.2014.07.01

9) G. Rui, X.-f. Song, X.-y. Zhang and G. Wu, Bull. Chin. Ceram. Soc., 33, 346-350 (2014).

10) J. H. Xia, D. W. Yuan and L. J. Wang, J. Wuhan Univ. Technol., 31, 25-28 (2009).

11) Y. Quanbin, Z. Shuqing and Y. Qianrong, Properties of a New typed Repairing Material, the Rapidly Hardened Phosphate Cement. CHINAL CONCRETE AND CEMENT PRODUCTS, 4 (2000).

12) Z.-y. Lai, J.-s. Qian, Z.-y. Lu, Q. Li and Q.-1. Zou, J. Wuhan Univ. Technol., 33, 16-20 (2011).

13) W. R. Eubank, J. Am. Ceram. Soc., 34, 225-229 (1951).

14) A. S. Wagh, S. Y. Jeong and D. Singh, Proc. 1st Int. Conf. High Strength Concrete, The American Society of Civil Engineers (1997) pp. 542-553.

15) J. M. Dong, H. F. Yu and L. M. Zhang, J. Salt Lake Res., 18, 38-41 (2010).

16) E. Soudée and J. Péra, Cement Concrete Res., 32, 153157 (2002).

17) Q. Yang and X. Wu, Cement Concrete Res., 29, 389396 (1999).

18) J. Yang, C. Qian, Q. Zhang, B. Jiao and X. Yan, J. Southeast Univ., (Nat. Sci. Ed.), 40, 373-379 (2010).

19) N. Yang, C. Shi, J. Yang and Y. Chang, J. Mater. Civil Eng. 26, 04014071 (2014).

20) Z. Ding and Z. Li, ACI Mater. J., 102, 375 (2005).

21) A. S. Wagh, "Chemically Bonded Phosphate Cement Ceramis", Elsevier Science Ltd, Oxford (2004).

22) Y. Liu, B. Chen and Z. Qin, Constr. Build. Mater., 264, 120728 (2020)

23) C. K. Chau, F. Qiao and Z. Li, Constr. Build. Mater., 25, 2911-2917 (2011). 